\title{
Corrigendum: Cam-Gears Forces, Velocities, Powers and Efficiency
} \author{
Apicella and ${ }^{2}$ Florian Ion T. Petrescu \\ ${ }^{1}$ Advanced Material Lab, Department of Architecture and Industrial Design, \\ Second University of Naples, 81031 Aversa (CE), Italy \\ ${ }^{2}$ ARoTMM-IFToMM, Bucharest Polytechnic University, Bucharest, (CE), Romania \\ ${ }^{3}$ Dean of School of Graduate Studies and Research, American University of Ras Al Khaimah, UAE \\ ${ }^{4}$ Union College, USA \\ ${ }^{5}$ University of Salamanca, Spain
}

${ }^{1}$ Raffaella Aversa, ${ }^{2}$ Relly Victoria V. Petrescu, ${ }^{3}$ Bilal Akash, ${ }^{4}$ Ronald B. Bucinell, ${ }^{5}$ Juan M. Corchado, ${ }^{1}$ Antonio

Correction to: American Journal of Engineering and Applied Sciences

http://doi.org/10.3844/ajeassp.2017.491.505, published online 27 April 2017; updated 29 August 2019

The original version of this Article contained Mr. MirMilad Mirsayar as a Co-

Author. Mr. Mirsayar has not contributed to the preparation and publication of this manuscript.

These errors have now been corrected in the HTML and PDF versions of the Article. http://doi.org/10.3844/ajeassp.2017.491.505. 